\author{
Marquette University \\ e-Publications@Marquette
}

School of Dentistry Faculty Research and

Publications

Dentistry, School of

$9-2011$

\title{
Association between Caries, Obesity and Insulin Resistance in Mexican Adolescents
}

\author{
Juan Pablo Loyola-Rodgriguez \\ San Luis Potosi University \\ Carlos Villa-Chavez \\ San Luis Potosi University \\ Nuria Patiño-Marin \\ San Luis Potosi University \\ Celia Aradillas-Garcia \\ San Luis Potosi University \\ Cesar Gonzalez \\ Marquette University, cesar.gonzalez@marquette.edu
}

See next page for additional authors

Follow this and additional works at: https://epublications.marquette.edu/dentistry_fac

Part of the Dentistry Commons

\section{Recommended Citation}

Loyola-Rodgriguez, Juan Pablo; Villa-Chavez, Carlos; Patiño-Marin, Nuria; Aradillas-Garcia, Celia; Gonzalez, Cesar; and de la Cruz-Mendoza, Esperanza, "Association between Caries, Obesity and Insulin Resistance in Mexican Adolescents" (2011). School of Dentistry Faculty Research and Publications. 242.

https://epublications.marquette.edu/dentistry_fac/242 


\section{Authors}

Juan Pablo Loyola-Rodgriguez, Carlos Villa-Chavez, Nuria Patiño-Marin, Celia Aradillas-Garcia, Cesar Gonzalez, and Esperanza de la Cruz-Mendoza 


\title{
Association between Caries, Obesity and Insulin Resistance in Mexican Adolescents
}

\author{
Juan Pablo Loyola-Rodriguez * / Carlos Villa-Chavez ** / Nuria Patiño-Marin *** / \\ Celia Aradillas-Garcia **** / Cesar Gonzalez ***** / Esperanza de la Cruz-Mendoza ******
}

\begin{abstract}
Aim: To determine the association among dental caries, obesity and insulin resistance in Mexican adolescents. Methods: Body Mass Index, obesity (OB) blood pressure, insulin level, insulin resistance (IR), triglycerides level, serum HDL-cholesterol (cHDL), DMFT index and salivary flow were measured. Results: Anthropometric measures showed a significant statistical difference $(p<0.05)$. Insulin level was 8.98 for healthy subjects, whereas for OB-IR group was 25.35, there was a statistical significant difference $(p<$ 0.05). Triglycerides level was 88.50 for healthy subjects and $169.40 \mathrm{mg} / \mathrm{dL}$ for OB-IR; $\mathrm{CHDL}$ was 52.88 for healthy and $41.82 \mathrm{mg} / \mathrm{dL}$ for OB-IR group, both showed a statistically significant difference $(p<0.05)$. Salivary flow was 4.30 for healthy and for OB-IR group was $5.48 \mathrm{ml} / \mathrm{min}$ showed a significant statistical difference $(p<0.05)$. DMFT index was 3.02 for healthy and for OB-IR adolescents was 4.78 , showed a significant statistical difference $(p<0.05)$. The caries component of DMFT index was 1.84 for healthy and was 3.52 for OB-IR adolescents, showed a significant statistical difference $(p<0.05)$. According to the multivariate analysis, DMFT (OR=3.10; IC95\%=0.20-1.02, $p=0.042)$ and decay $(O R=3.30 ;$ IC95\%=0.19-1.0, $p=0.011)$ were associated with subjects with OB-IR. Conlusion: OB-IR Mexican adolescents showed a positive association with DMFT.
\end{abstract}

Keywords: caries, obesity, insulin resistance, children, Mexico

J Clin Pediatr Dent 36(1): 49-54, 2011

\section{INTRODUCTION}

$\mathrm{D}$ espite the efforts to diminish dental caries around the world, there are only few positive results in industrialized countries, where the population has access to primary care from early ages. ${ }^{1}$ Previous studies

* Juan Pablo Loyola-Rodriguez,DDS, PhD, Head and Chairman, Master's Degree in Dental Science with Specialization in Advanced General Dentistry Program, San Luis Potosi University, Mexico.

** Carlos Villa-Chavez, 2nd year Resident, Master's Degree in Dental Science with Specialization in Advanced General Dentistry Program, San Luis Potosi University, Mexico.

*** Nuria Patiño-Marin, Associate Professor, Master's Degree in Dental Science with Specialization in Advanced General Dentistry Program, San Luis Potosi University, Mexico.

**** Celia Aradillas-Garcia, Head and Chairman, Laboratory of Hormones and Nuclear Medicine San Luis Potosí, University, México.

***** Cesar D. Gonzalez, Director, Division of Pediatric Dentistry, Marquette University, Wisconsin, USA.

****** Esperanza de la Cruz-Mendoza, Clinical Associate, Laboratory of Hormones and Nuclear Medicine, San Luis Potosí University, México.

Send all correspondence to: Juan Pablo Loyola Rodríguez, Mariano Avila \#295-2, Col. Tequisquiapam, CP 78250, San Luis Potosí, SLP, México.

Tel: 524448262361 ext. 102

Fax: 524448262361 ext. 104

Email: jloyola@uaslp.mx have reported high caries prevalence in Latin American countries where a great proportion of the children population remains without dental treatment. ${ }^{2,3}$

The increase in food consumption with high glycemic and caloric components (sucrose) not only causes dental caries, but it also entails obesity. ${ }^{4}$ Obesity is a subject of global nutritional interest, especially in childhood the obesity has more than tripled in the past 30 years, the prevalence in children aged 6 to 11 years increased from $6.5 \%$ in 1980 to $19.6 \%$ in 2008 . Similar findings has been reported in adolescents, the prevalence of obesity among adolescents aged 12 to 19 years increased from $5.0 \%$ to $18.1 \%{ }^{5,6}$ The National Health and Nutrition Survey (NHANES) conducted in 2003-2006 reported an obesity prevalence of $22.1 \%$ in men and $19.9 \%$ in women in Mexican-Americans adolescents aged 12 to 19 years. $^{7}$ These results exceed the prevalence of obesity reported in Mexico, it was reported 9.2 to $11.8 \%$ for adolescent men aged 12 to 17 and 6.8 to $10.6 \%$ for adolescent woman aged 10 to 17 years. ${ }^{8}$

Insulin resistance (IR) is a metabolic state in which the physiological insulin concentrations produce an inferior physiological response. The IR is the decrease of action of this hormone in muscular, hepatic and fatty tissues, and it manifests when a determined concentration of the hormone produces a smaller biological effect. ${ }^{9}$ Mexico has a population with high risk of developing diabetes since levels of glucose intolerance are as high as $14.7 \%$ in a population 
from 20 to 69 years old. ${ }^{10}$ When this percentage is added to the population that already presents high levels of glucose or are not diagnosed, it means that at least $10.7 \%$ of the total population in this age group have or will have diabetes mellitus. Based on this information, there are nearly 6.5 to 110 million diabetics in Mexico and more than 2 millions have not been diagnosed. ${ }^{11}$ To worst this health situation, it has been reported that children spend more time watching television or playing with the computer than exercising, they spend on average 25 to 27 hours per week watching television and 1.6 hours per week in physical activity. ${ }^{1,10}$ The probability of overweight is 4.6 times higher for those that watch 5 hours of television per day compared to those that watch television less than 2 hours per day. ${ }^{1}$

A recent study in elementary school reported a positive correlation between obesity and caries experience in primary dentition in Mexican population ${ }^{12}$ and other studies have reported a positive association in primary and mixed dentitions as well. ${ }^{13,14}$ However, there has been reported an inverse relationship between dental caries and overweight. ${ }^{1,15,16}$ Recently, there is a report about a positive association of proximal caries with overweight and obesity in adolescents, ${ }^{17}$ but in adolescents there is a few information about this problem health. Due to which carrying out a study with a population of high risk to obesity, Type 2 Diabetes Mellitus, and with a high prevalence of dental decay as the Mexican is going to contribute to the knowledge of this association. The aim of the present study was to determine the association among caries experience and obesity-insulin resistance in Mexican adolescents aged 12 to 18 years.

\section{METHOD AND MATERIALS}

A cross-sectional study was carried out in oral medicine clinic of the Faculty of Dentistry and in the Laboratory of Hormones and Nuclear Medicine of the Faculty of Medicine, both at San Luis Potosí University, Mexico. The clinical research committee approved the study in accordance with the ethical guidelines of the declaration of Helsinki (version 2008).

Parents of children completed a standardized health questionnaire that included information about pediatrics and oral evaluations and an informed voluntary written consent from parents was obtained prior to clinical examinations. Anthropometric measures, arterial pressure, and blood and saliva samples were included for each patient as well. The selection of the subjects were carried out by using the following criteria: 1) Inclusion criteria: Group A. subjects with absence of OB-IR, age between 12 and 18 years old, and presence of permanent teeth were included. Group B. patients with diagnosis of obesity and insulin resistance (OB-IR), subjects from 12 and 18 years old, and presence of permanent teeth were included. 2) Exclusion criteria for both groups were as follows: patients affected by diabetes mellitus and subjects with evident genetic disorders. 3) Elimination criteria: technical incapacity to establish the diagnosis of obesity and insulin resistance and to evaluate the variables included in the study.
From a total of 350 evaluated individuals, 100 subjects that fulfill the selection criteria were selected and divided into two groups. Group A: 50 healthy subjects without OBIR and Group B: 50 patients with diagnosis of OB-IR. The study was blinded for obesity and insulin resistance diagnoses. A 10 milliliter of peripheral blood was taken and centrifuged 3,500 rpm/10 min; then, serum was separated and stored at $-80^{\circ} \mathrm{C}$ until experimental procedures. Determination of plasma glucose levels, serum HDL-cholesterol (cHDL) and triglycerides were measured by using a Hitachi 902 automatic analyzer (Roche Diagnostics, Japan). Determination of insulin was carried out by quimioluminiscence (QLA) (IMMULITE 1000 analyzer DPC, Los Angeles, CA, USA). Insulin resistance degree was determined by the homeostatic model assessment. ${ }^{18}$ Scores ordinarily range from 0 to 15 , higher scores indicated an insulin resistance, which was calculated as the product of the fasting plasma insulin level (in microunits per milliliter) and the fasting glucose level (in millimoles/l) divided by 22.5 .

\section{Anthropometric measures}

Height was measured with the participants standing without shoes by using a stadiometer, and was recorded to the nearest half centimeter. Weight was measured by a digital scale, with the participants wearing light clothing or underwear, and was recorded to the nearest 100 g. Waist-HipRatio was defined as follows: waist circumference was measure at the narrowest part between the lower rib and the iliac crest (the natural waist) or, in case of an indeterminable waist narrowing, halfway between the lower rip and the iliac crest, and was recorded to the nearest half centimeter. Body Mass Index (BMI) was calculated as weight in kilograms divided by the square of height in meters and was rounded to the nearest tenth. The index of hip and waist was calculated dividing the waist circumference by the hip measure, a value up to 0.9 in men and 0.8 in women was associated with higher incidence of insulin resistance. ${ }^{19}$

\section{Overweight and obesity}

Obesity and overweight status were defined based on the age and sex-specific 2000 CDC growth charts for the United States. ${ }^{20}$ Obesity was defined as at or above the 95 th percentile of BMI for age and sex; overweight was defined as at or above the 85 th percentile and less than 95 th percentile of BMI for age and sex. Normal weight was defined as less than 85 th percentile of BMI for age and sex.

\section{Blood pressure}

Blood pressure (BP) was measured in a seated position after at least 5 min rest with a Dinamap semiautomatic oscillometric recorder. A cuff of suitable size was applied to the participant's upper arm (the arm not used for blood collection), which was supported by a table at heart level. BP was measured with a standard mercury sphygmomanometer using the first and fifth Korotkoff sounds, to the nearest 2 $\mathrm{mmHg}$. The normal value of BP was $100 / 60$ up to $120 / 80$, values over $130 / 90 \mathrm{mmHg}$ were indicative of hypertension. 


\section{Saliva sampling}

Paraffin-stimulated whole saliva from subjects was sampled over a 5-min period in a sterilized propylene tube; this procedure was carried out consistently in the morning (9-10 am) to minimize the circadian rhythm effects, $2 \mathrm{~h}$ after the previous meal. ${ }^{21}$ The quantification of the salivary flow was determined by dividing the whole saliva sample (in milliliters) between harvesting time, $\mathrm{pH}$ was estimated by a potentiometer (Orion 720A, Boston, MA, the USA) for its calibration buffers $\mathrm{pH} 4$ and 7 were used. The buffer capacity was measured by Checkbuf Decay Risk Checker CR-20 kit in agreement to the specifications of the manufacturer (Morita Co., Kyoto, Japan). The salivary secretion was determined according to the following parameters: more than 5.0 milliliter (sufficient) from 3.5 to 5.0 milliliter (moderate) and less than 3.5 milliliter (low). The saliva buffer capacity was analyzed under the following parameters: $\mathrm{pH}$ up to 5.8 (high), 4.8 to 5.8 (moderate) and $<4.8$ (low).

\section{Dental Caries Index}

The WHO caries diagnostic criteria were used for determining the permanent tooth DMFT index (decayed, missing and filled tooth surfaces).

\section{Statistical analysis}

Before starting the study, two examiners were calibrated in all variables with an expert in dental caries through Kappa test. All variables are expressed as mean, standard deviation, and range. Shapiro-Wilks, Levine and Brown Forsythe tests were used to determine the distribution of variables. The non-parametric Mann Whitney $\mathrm{U}$ test was used to compare continuous variables and $\mathrm{X}^{2}$ of Mantel-Haenszel test was used to compare categorical variables. A binary logistic regression multivariate analysis was carried out to estimate the association among DMFT, decay, and $\mathrm{pH}$ of saliva. The diagnosis of obesity and insulin resistance was established as a dichotomous dependent variable. The independent variables were DMFT, decay and $\mathrm{pH}$ of saliva. All statistical test were carried out by JMP program version 8.0 and Statview version 4.0 (both for SAS Institute, USA), statistical significance was set at $\mathrm{p}<0.05$.

\section{RESULTS}

Before starting the study, two examiners were calibrated in all variables with an expert in each variable by using the intraclass correlation coefficient, obtaining 0.98 as result. From 100 selected subjects, 50 were healthy and 50 were diagnosed with obesity and insulin resistance (OB-IR). The healthy subjects 29 women (58\%) and 21 men (42\%) had a mean age of $13.08 \pm 1.06$ years old and it was reported a familial antecedents (FA) of diabetes mellitus in $31(62 \%)$. The age distribution of OB-IR group, 27 (54\%) were women and $23(46 \%)$ were men, with a mean of $13.0 \pm 1.17$ years old, reported FA of Mellitus Diabetes in $42(84 \%)$ and a frequency of Insulin Resistance Syndrome (IRS) of 9 (18\%). A statistically significant difference was observed for FA ( $p=$ $0.0132)$ and for IRS $(p=0.0017)$ between groups.
Table 1, depicts the comparisons of the anthropometric measures between groups, most variables showed a significant statistical difference between groups $(p<0.05)$. However, there was no statistical difference when comparing groups $(p>0.05)$ about age.

In Table 2, insulin level of 9.0 is reported in healthy subjects, whereas for the patients with OB-IR was 25.4, obtaining significant statistical difference $(p<0.05)$. The systolic arterial pressure showed an average of 109.3 in the healthy group and for OB-IR group was $114.3 \mathrm{~mm} \mathrm{Hg}$, there was a statistical significant difference $(p<0.05)$. In the variable triglycerides an average of 88.5 was obtained for healthy subjects and $169.4 \mathrm{mg} / \mathrm{dL}$ in patients with OB-IR, cHDL displayed a mean of 52.8 for control group and $41.8 \mathrm{mg} / \mathrm{dL}$ for OB-IR group; both variables were statistically significant when groups were compared $(p<0.05)$. The systolic arterial pressure showed a significant statistical difference $(p<0.05)$ between groups as well. The variables cholesterol, glucose and diastolic arterial pressure did not observe statistically significant differences when groups were compared $(p>$ $0.05)$.

Table1. Comparison anthropometric measures of the adolescents in the study groups.

\begin{tabular}{|c|c|c|c|c|c|}
\hline & \multicolumn{2}{|c|}{$\begin{array}{l}\text { Healthy } \\
n=50\end{array}$} & \multicolumn{2}{|c|}{$\begin{array}{c}\text { OB-IR } \\
n=50\end{array}$} & \multirow[b]{2}{*}{$p$} \\
\hline & Mean \pm SD & Range & Mean \pm SD & Range & \\
\hline Age (years) & $13.1 \pm 1.1$ & $12.0-15.0$ & $13.0 \pm 1.2$ & $12.0-15.0$ & 0.7277 \\
\hline Weight (kg) & $46.9 \pm 8.0$ & $31.5-62.0$ & $68.8 \pm 2.3$ & $70.4-101.0$ & 0.0001 \\
\hline Height (m) & $1.6 \pm 0.1$ & $1.4-1.8$ & $1.6 \pm 0.1$ & $1.5-1.9$ & 0.0094 \\
\hline BMI (kg/mt²) & $19.1 \pm 2.2$ & $15.7-23.7$ & $29.2 \pm 3.1$ & $25.0-39.0$ & 0.0001 \\
\hline Waist (cm) & $73.5 \pm 7.2$ & $52.0-86.0$ & $97.4 \pm 8.9$ & $75.0-119.0$ & 0.0001 \\
\hline Hip (cm) & $84.8 \pm 7.3$ & $65.0-96.0$ & $104.7 \pm 8.8$ & $86.0-129.0$ & 0.0001 \\
\hline WHR (cm) & $0.9 \pm 0.1$ & $0.8-1.0$ & $0.9 \pm 0.1$ & $0.8-1.0$ & 0.0001 \\
\hline
\end{tabular}

SD: standard deviation; $\mathrm{kg}$ : kilograms; $\mathrm{m}$ : meter; $\mathrm{cm}$; centimeter; $\mathrm{kg} / \mathrm{mt}^{2}$ : weight in kilograms divided between height in meters to the square; BMI: Body Mass Index; WHR: Waist-Hip-Ratio; Statistical test used: Mann-Whitney U.

Table 2. Comparison of insulin, glucose, cholesterol, triglycerides, $\mathrm{HDL}$, arterial pressure (systolic and diastolic) of the adolescents groups.

\begin{tabular}{llllll}
\hline & \multicolumn{2}{c}{$\begin{array}{c}\text { Healthy } \\
n=50\end{array}$} & \multicolumn{2}{c}{$\begin{array}{c}\text { OB-IR } \\
n=50\end{array}$} \\
& Mean $\pm \mathrm{SD}$ & Range & Mean $\pm \mathrm{SD}$ & Range & $p$ \\
\hline Insulin $(\mu \mathrm{Ul} / \mathrm{mL})$ & $9.0 \pm 3.0$ & $2.0-14.0$ & $25.4 \pm 10.0$ & $15.3-53.7$ & 0.0001 \\
Glucose $(\mathrm{mg} / \mathrm{dll})$ & $88.2 \pm 9.2$ & $65.0-108.0$ & $89.2 \pm 9.8$ & $66.0-121.0$ & 0.6817 \\
Triglycerides $(\mathrm{mg} / \mathrm{dl})$ & $88.5 \pm 33.4$ & $39.0-198.0$ & $169.4 \pm 174.6$ & $56.0-1250.0$ & 0.0001 \\
HDL $(\mathrm{mg} / \mathrm{dl})$ & $52.88 \pm 14.85$ & $24.0-111.0$ & $41.8 \pm 8.7$ & $26.0-62.0$ & 0.0001 \\
Systolic $(\mathrm{mmHg})$ & $109.38 \pm 12.66$ & $80.0-150.0$ & $114.3 \pm 10.5$ & $90.0-140.0$ & 0.0452 \\
Diastolic $(\mathrm{mmHg})$ & $71.00 \pm 9.74$ & $60.0-110.0$ & $73.5 \pm 7.4$ & $60.0-90.0$ & 0.1082 \\
\hline
\end{tabular}

SD: Standard deviation; $\mathrm{CHDL}$ : Cholesterol together with $\mathrm{HD}$ lipoproteins; $\mu \mathrm{UI} / \mathrm{mL}$ : micro international units divided between milliliters; $\mathrm{mg} / \mathrm{dl}$ : milligrams divided between deciliters; mmHg: millimeters of mercury; Statistical test used: MannWhitney U. 
Table 3. Comparisons of salivary flow and $\mathrm{pH}$, and DMFT index of the study groups.

\begin{tabular}{llllll}
\hline & \multicolumn{2}{c}{$\begin{array}{c}\text { Healthy } \\
n=50\end{array}$} & \multicolumn{2}{c}{$\begin{array}{c}\text { OB-IR } \\
n=50\end{array}$} \\
\hline & Mean \pm SD & Range & Mean \pm SD & Range & $p$ \\
\hline Insulin $(\mu \mathrm{Ul} / \mathrm{mL})$ & $9.0 \pm 3.0$ & $2.0-14.0$ & $25.4 \pm 10.0$ & $15.3-53.7$ & 0.0001 \\
Salivary flow $(\mathrm{mL} / \mathrm{min})$ & $4.30 \pm 2.64$ & $0.90-13.70$ & $5.48 \pm 2.89$ & $1.0-14.20$ & 0.0172 \\
pH salivary & $7.29 \pm 0.47$ & $6.4-8.8$ & $7.31 \pm 0.33$ & $6.50-7.90$ & 0.4971 \\
DMFT & $3.02 \pm 1.82$ & $0.00-8.00$ & $4.78 \pm 3.30$ & $0.00-12.00$ & 0.0016 \\
$\quad$ Decay & $1.84 \pm 3.35$ & $0.00-14.0$ & $3.52 \pm 2.84$ & $0.00-10.00$ & 0.0008 \\
Missing & $0.16 \pm 0.24$ & $0.00-6.0$ & $0.10 \pm 0.70$ & $0.00-1.00$ & 0.7303 \\
Filled & $1.02 \pm 1.35$ & $0.00-6.0$ & $1.16 \pm 1.63$ & $0.00-7.00$ & 0.8254 \\
\hline
\end{tabular}

SD: Standard deviation; $\mathrm{mL} / \mathrm{min}$ : Milliliters per minute; DMFT: Decay, Missing and Filled Teeth; Statistical

test used: Mann-Whitney U.

Table 3 shows a salivary flow mean of $4.30 \mathrm{ml} / \mathrm{min}$ for control group and for OB-IR group was $5.48 \mathrm{ml} / \mathrm{min}$, there was a significant statistical difference $(\mathrm{p}<0.05)$ between groups. The salivary $\mathrm{pH}$ in healthy subjects was 7.29 and for OB-IR group was 7.31, there was no statistical difference (p $>0.05$ ) between the groups. DMFT index showed a mean of 3.02 in the healthy adolescents group, but in OB-IR group was 4.78; there was a significant statistical difference $(\mathrm{p}<$ 0.05). When detaching DMFT index and evaluating separately each component, it could be observed that only the decay component showed a significant statistical difference ( $\mathrm{p}<0.05)$; whereas both missing and filled teeth components showed no statistical difference $(\mathrm{p}>0.05)$. According to the multivariate analysis, DMFT (OR $=3.10$; IC95\% = $0.20-1.02, p=0.042)$ and decay $(\mathrm{OR}=3.30 ; \mathrm{IC} 95 \%=0.19$ $-1.0, p=0.011)$ were associated with subjects with obesity and insulin resistance.

\section{DISCUSSION}

Most reports about the association of decay dental-obesity have been carried out in children population. In Mexico, there are reports of a high frequency of obesity in children population, it could be explained due to sport programs in elementary schools does not exist and the little that exists, it is directed to masculine sex, being less opportunities of sport for women. ${ }^{22}$

The insulin is the main regulator of the homeostasis of glucose and lipids, the association of obesity with insulin resistance syndrome (IRS) is closed related, so the risk of cardiovascular disease not only is related to the obesity degree, but it depends on the distribution of the fat in the human body. ${ }^{23}$ Obesity in children and adolescents represents an important risk factor for IR, independent of sex, age, or race/ethnicity. The insulin resistance syndrome (IRS) is a set of factors of cardiovascular risk related to obesity and IR, it has been reported that obesity increased in children and adolescents from 2.3 to $17.1 \%$ being observed with aterogenic lipid profile and higher levels of glycemia. ${ }^{24}$ The IRS has increased as much in the last decade in general population (6.4-10\%) and in obese population (28.7-32.1\%), ${ }^{23}$ it was reported a positive correlation between IRS and obesity, where severe IRS affects $22.7 \%$ to slight obese and $40.3 \%$ to severe obese population. ${ }^{24}$ In the present study an IRS frequency of 9 (18\%) in experimental group was found. Unfortunately, we can no compare the above mentioned studies due to the differences in inclusion criteria and sample size used.

When analyzing the association between the magnitude of the obesity with each of the anthropometric components, arterial hypertension has been reported with a positive association, which agrees with the results obtained in our study, were the systolic arterial pressure showed significant statistical difference in OB-IR patients. ${ }^{25}$ In the population evaluated in this study, the FA showed significant statistical difference with a frequency of $42(84 \%)$ in OB-IR group and $31(62 \%)$ in control group, which is similar to a study of 126 adolescents (8-13 years old) with FA of DM, where obese subjects displayed a prevalence of cholesterol together with lipoproteins (cHDL) and elevated systolic arterial pressure. These results confirm the findings in adolescents, where a high proportion of obese adolescents have higher risked of type $2 \mathrm{DM}$ and cardiovascular disease. ${ }^{26}$

In spite of the efforts made anywhere in the world to diminish the incidence and prevalence of dental decay, there are positive results only in the industrialized countries, ${ }^{1}$ but the opposite scenario is in the developing countries where the access to dental care is limited and where the culture of the prevention is not carried out in most Latin American countries. ${ }^{2,3}$ In Mexico decay prevalence of $91.6 \%$ in urban areas and $54.4 \%$ in countryside has been reported. ${ }^{2}$ In the present study, dental decay prevalence was $74 \%$ in healthy adolescents and $84 \%$ in OB-IR adolescents, when DMFT index was detaching and each component was evaluated separately, it could be observed that decay and missing teeth components showed a significant statistical difference. These results suggest that in adolescent population of high risk to IR and DM, there is evidence of a positive association between the obesity and dental decay. The results agree with other studies in which it was determined a positive association between dental decay and obesity. ${ }^{13,14}$ Since in Mexico there is just a report about dental decay experience in adolescent population ( $4.04 \pm 3.90)$, it is difficult to make comparatives analysis with this study mainly due to sample size. ${ }^{27}$ However, this study showed that caries experience in the healthy group was very similar $(4.58 \pm 3.43)$, but OB-IR adolescents showed a higher caries experience $(6.08 \pm 5.06)$ in similar age population. Independently of comparisons, it is important to mention that the dental decay continues being an oral health problem in Mexico.

Several studies have considered saliva as a vehicle to diagnose factors associated to dental decay. In this study several traits of saliva were included, salivary flow, $\mathrm{pH}$, and buffer capacity as main risk factors. Nevertheless, some of them such as salivary flow are influenced by the age, weight, method used and collaboration of the patient, which affects the obtained results. In the present report salivary flow was higher in OB-IR patients, which suggests a better protection against dental caries by salivary clearance of bacterial 
biofilm on the teeth. However, it has been reported that obesity is associated with reduced flow rate of stimulated saliva, ${ }^{28}$ it could be more important the saliva amount of organic and inorganic components to protect against dental caries rather than the salivary flow. Buffer capacity is an important trait of saliva, since its capacity depends to reduce $\mathrm{pH}$ resulting of bacterial action on sucrose substrates found in dental plaque to avoid acid attack that produces enamel demineralization. The results of the present study in both groups displayed a high buffer capacity, which is opposite to other reports that indicated that the patients with decay display an altered buffer capacity. ${ }^{29}$ These discrepancies can be explained by the different inclusion criteria (age, sex, weight, sample size, type of teething and used method to measure capacity buffer). The $\mathrm{pH}$ in general terms is an indicator of the bacterial activity, it has been described that saliva normal $\mathrm{pH}$ is 7 in caries-free patients, tending slightly to acidity in caries-active patients. ${ }^{21}$ Recent studies reported a $\mathrm{pH}$ mean of 6.79 , the mean obtained in the present study in healthy subjects was 7.29 and for the OB-IR group was 7.31; therefore, in this study $\mathrm{pH}$ was not an important factor. ${ }^{30}$

\section{CONCLUSIONS}

In a Mexican adolescents sample population with and without OB-IR, DMFT index showed a significant statistical difference $(p<0.05)$ between groups. When DMFT index was detaching into its components and evaluating each separately, it could be observed a positive association between OB-IR with decay teeth $(p<0.05)$. According to the multivariate analysis, DMFT $(\mathrm{OR}=3.10 ; \mathrm{IC} 95 \%=0.20-1.02, p$ $=0.042)$ and decay $(\mathrm{OR}=3.30 ;$ IC95\% $=0.19-1.0, p=$ 0.011 ) were associated with subjects with obesity and insulin resistance.

\section{REFERENCES}

1. Palmer CA. Dental caries and obesity in children: different problems, related causes. Quintessence Int, 36: 457-461, 2005

2. Irigoyen ME, Luengas IF, Yashine A, Mejia AM, Maupome G. Dental caries experience in Mexican schoolchildren from rural and urban communities. Int Dent J, 50: 41-45, 2000.

3. Elías Boneta AR, Crespo Kebler K, Gierbolini CC, Toro Vizcarrondo CE, Psoter WJ. Dental Caries Prevalence of twelve year olds in Puerto Rico. Community Dent Health, 20: 171-176, 2003.

4. Tinanoff N. Association of diet with caries in preschool children. Dent Clin North Am, 49: 725-737, 2005.

5. Ogden CL, Carroll MD, Curtin LR, Lamb MM, Flegal KM. Prevalence of high body mass index in US children and adolescents, 2007-2008. JAMA, 303: 242-249, 2010.

6. National Center for Health Statistics. Health, United States, 2004 with Chartbook on Trends in the Health of Americans. Hyattsville, MD; 2004. http://www.cdc.gov/nchs/data/hus/hus04trend.pdf\#070

7. National Health and Nutrition Survey (NHANES Survey 2003-2006). http://www.cdc.gov/obesity/childhood/prevalence.html

8. Encuesta Nacional de Salud y Nutrición-ENSANUT 2006. http://www.insp.mx/ensanut/resultados_ensanut.pdf.

9. Le Roith D, Zick Y. Recent advance in our understanding of insulin action and insulin resistance. Diabetes Care, 24: 588-597, 2001.

10. Federación Mexicana de Diabetes, A.C. http://www.fmdiabetes.org/ v2/paginas/d_numeros.php.

11. Kahn SE, Hull RL, Utzschneider KM. Mechanisms linking obesity to insdulin resistance and type diabetes. Nature, 444: 840-846, 2006
12. Vazquez-Nava F, Vazquez-Rodriguez EM, Saldivar-Gonzalez AH, LiOchoa D, Martinez-Perales GM, Joffre-Velazquez VM. Association between obesity and dental caries in a group of preschool children in Mexico. J Public Health Dent, 70: 124-130, 2010.

13. Hilgers KK, Kinane DE, Scheetz JP. Association between childhood obesity and smooth-surface caries in posterior teeth: a preliminary study. Pediatr Dent, 28: 23-28, 2006.

14. Kantovitz KR, Pascon FM, Rontani RM, Gaviao MB. Obesity and Dental Caries. A systematic review. Oral Health Prev Dent, 4: 137-144, 2006.

15. Macek MD, Mitola DJ. Exploring the association between overweight and dental caries among US children. Pediatr Dent, 28: 375-380, 2006.

16. Moreira PV, Rosenblatt A, Severo AM. Prevalence of dental caries in obese and normal-weight Brazilian adolescents attending state and private schools. Community Dent Health, 23: 251-253, 2006.

17. Alm A, Fahraeus C, Wendt LK, Koch G, Andersson-Gare B, Birkhed D. Body adiposity status in teenagers and snacking habits in early childhood in relation to approximal caries at 15 years of age. Int J Paediatr Dent, 18: 189-196, 2008.

18. Matthews DR, Hosker JP, Rudenski AS, Naylor BA, Treacher DF, Turner RC. Homeostasis model assessment: insulin resistance and beta-cell function from fasting plasma glucose and insulin concentrations in man. Diabetologia, 28: 412-419, 1985.

19. Pinhas-Hamiel O, Lerner-Geva L, Copperman N, Jacobson MS. Insulin resistance and parenteral obesity as predictors to response to therapeutic life style change in obese children and adolescents 10-18 years old. J Adolesc Health, 43: 437-443, 2008.

20. Flegal KM, Ogden CL, Wei R, Kuczmarski RL, Johnson CL. Prevalence of overweight in US children: comparison of US growth charts from the Centers for Disease Control and Prevention with other reference values for body mass index. Am J Clin Nutr, 73: 1086-1093, 2001.

21. Loyola-Rodriguez JP, Martinez-Martinez RE, Flores-Ferreyra BI, Patiño-Marin N, Alpuche-Solis AG, Reyes-Macias JF. Distribution of Streptococcus mutans and Streptococcus sobrinus in saliva of Mexican caries-free and caries-active children by microbial and molecular (PCR) assays. J Clin Pediatr Dent, 32: 121-126, 2008.

22. Halley Castillo E, Borges G, Talavera JO, Orozco R, Vargas-Aleman C, Huitron-Bravo G, Diaz-Montiel JC, Castañon S, Salmeron J. Body mass index and the prevalence of metabolic syndrome among children and adolescents in two Mexican populations. J Adolesc Health, 40: 521-526, 2007.

23. Weiss R, Dziura J, Burgert TS, Tamborlane WV, Taksali SE, Yeckel CW, Allen K, Lopes M, Savoye M, Morrison J, Sherwin RS, Caprio S. Obesity and the metabolic syndrome in children and adolescents. New Engl J Med, 350: 2362-2374, 2004.

24. Ogden CL, Carroll MD, Curtin LR, McDowell MA, Tabak CJ, Flegal KM. Prevalence of overweight and obesity in the United States, 19992004. J Am Med Assoc, 295: 1549-1555, 2006.

25. Burrows AR, Leiva BL, Weistaub G, Ceballos SX, Gattas ZV, Lera ML, Albala BC. Prevalence of metabolic syndrome in a sample of children consulting in an obesity clinic. Rev Med Child, 135: 174-181, 2007.

26. Cruz ML, Weigensberg MJ, Huang TT, Ball G, Shibai GQ, Goran MI. The metabolic syndrome in overweight Hispanic youth and the role of insulin sensitivity. J Clin Endocrinol Metab, 89:108-113, 2004.

27. Garcia-Cortes JO, Medina-Solis CE, Loyola-Rodriguez JP, Mejia-Cruz JA, Medina-Cerda E, Patiño-Marin N, Pontigo-Loyola AP. Dental caries' experience, prevalence and severity in Mexican adolescents and young adults. Rev Salud Publica, 11: 82-91, 2009.

28. Modeer T, Blomberg CC, Wondimu B, Julihn A, Marcus C. Association between obesity, flow rate of whole saliva, and dental caries in adolescents. Obesity 18: 2367-2673, 2010.

29. Humprey SP, Williamson RT. A Review of Saliva: normal composition, flow and function. J Prosth Dent, 85: 162-169, 2001.

30. Fenoll-Palomares C, Muñoz Montagud JV, Sanchiz V, Herreros B, Hernandez V, Minguez M, Benages A. Unstimulated salivary flow rate, $\mathrm{pH}$ and buffer capacity of saliva in healthy volunteers. Rev Esp Enferm Dig, 96: 773-783, 2004. 
